\title{
A decade of living lobar lung transplantation: Recipient outcomes
}

\author{
Vaughn A. Starnes, MD \\ Michael E. Bowdish, MD \\ Marlyn S. Woo, MD \\ Richard G. Barbers, MD \\ Felicia A. Schenkel, RN \\ Monica V. Horn, RN \\ Renzo Pessotto, MD \\ Eric M. Sievers, MD \\ Craig J. Baker, MD \\ Robbin G. Cohen, MD \\ Ross M. Bremner, MD, PhD \\ Winfield J. Wells, MD \\ Mark L. Barr, MD
}

From the University of Southern California
Keck School of Medicine and Childrens
Hospital Los Angeles, Los Angeles, Calif.
Dr Bowdish was the recipient of the 2002
American Society of Transplant Surgeons
Thoracic Surgery Fellowship. Dr Barr was
supported in part by grants from the Heart
and Lung Surgery Foundation of Los An-
geles and the University of Southern Cali-
fornia University Hospital. Additional
funding was provided by the Hastings
Foundation.

Read at the Eighty-third Annual Meeting of The American Association for Thoracic Surgery, Boston, Mass, May 4-7, 2003.

Received for publication May 3, 2003; revisions requested June 20, 2003; accepted for publication July 7, 2003.

Address for reprints: Mark L. Barr, MD, Department of Cardiothoracic Surgery, University of Southern California, 1510 San Pablo St, Suite 415, Los Angeles, CA 90033 (E-mail: mbarr@surgery.usc.edu).

J Thorac Cardiovasc Surg 2004;127:114-22 $0022-5223 / \$ 30.00$

Copyright ( $\odot 2004$ by The American Association for Thoracic Surgery

doi:10.1016/j.jtcvs.2003.07.042
Objective: Living lobar lung transplantation was developed as a procedure for patients considered too ill to await cadaveric transplantation.

Methods: One hundred twenty-eight living lobar lung transplantations were performed in 123 patients between 1993 and 2003. Eighty-four patients were adults (age, $27 \pm 7.7$ years), and 39 were pediatric patients (age, $13.9 \pm 2.9$ years).

Results: The primary indication for transplantation was cystic fibrosis (84\%). At the time of transplantation, $67.5 \%$ of patients were hospitalized, and $17.9 \%$ were intubated. One-, 3-, and 5-year actuarial survival among living lobar recipients was $70 \%, 54 \%$, and $45 \%$, respectively. There was no difference in actuarial survival between adult and pediatric living lobar recipients $(P=.65)$. There were 63 deaths among living lobar recipients, with infection being the predominant cause $(53.4 \%)$, followed by obliterative bronchiolitis (12.7\%) and primary graft dysfunction (7.9\%). The overall incidence of acute rejection was 0.8 episodes per patient. Seventy-eight percent of rejection episodes were unilateral. Age, sex, indication, donor relationship, preoperative hospitalization status, use of preoperative steroids, and HLA-A, HLA-B, and HLA-DR typing did not influence survival. However, patients on ventilators preoperatively had significantly worse outcomes (odds ratio, $3.06, P=.03$; Kaplan-Meier $P=.002)$, and those undergoing retransplantation had an increased risk of death (odds ratio, 2.50).

Conclusion: These results support the continued use of living lobar lung transplantation in patients deemed unable to await a cadaveric transplantation. We consider patients undergoing retransplantations and intubated patients to be at significantly high risk because of the poor outcomes in these populations.

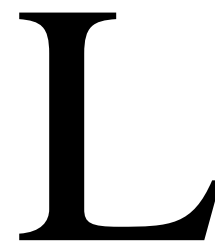

iving lobar lung transplantation was introduced in 1993 in response to the mismatch between supply and demand for those individuals awaiting lung transplantation. The number of available cadaveric organs has remained relatively stable since 1993, despite the liberalization of the standard donor criteria and the use of older and potentially more marginal donors. ${ }^{1-3}$ These trends have led to a leveling off of the annual lung transplantation rate, a doubling of the median waiting 
time, and an increase in the number of candidates who die while awaiting transplantation. ${ }^{2}$

With living lobar lung transplantation, right and left lower lobes from 2 healthy donors are implanted in the recipient in place of whole right and left lungs, respectively. Initial and intermediate survival, as well as functional outcomes, have been previously reported, with acceptable results. ${ }^{1,4-11}$ The purpose of this study is to expand on our series by providing an analysis of recipient outcomes during our first decade of experience with this procedure.

\section{Methods}

\section{Study Subjects and Design}

Between January 1993 and December 2002, inclusive, 128 living lobar lung transplantations were performed in 123 patients at the University of Southern California University Hospital and Childrens Hospital Los Angeles. Eighty-four patients were adults ( $\geq 18$ years of age), and 39 were pediatric patients ( $<18$ years of age). These patients constitute the cohort of patients for this outcomes analysis.

\section{Living Lobar Lung Transplantation}

All lobar recipients fulfilled the criteria for cadaveric lung transplantation and were listed with the United Network for Organ Sharing. Living lobar lung transplant recipients were selected on the basis of a deterioration of their clinical status with the expectation that a cadaveric donor would not become available or that further deterioration would make them unsuitable candidates for cadaveric transplantation.

The process of living-donor selection and the techniques of right and left donor lobectomy have been described previously. ${ }^{1,4,5,7,8,11,12}$ All lobar lung transplant procedures were performed through a transverse thoracosternotomy with the use of cardiopulmonary bypass and using a running polypropylene suture for the bronchial anastomosis. All patients received triple immunosuppressive therapy consisting of cyclosporine (INN: ciclosporin) or tacrolimus, azathioprine or mycophenolate mofetil, and prednisone, without the use of prophylactic monoclonal or polyclonal antibodies. ${ }^{7,11}$ All patients received standardized prophylaxis against Candida species, Pneumocystis carinii, and cytomegalovirus (CMV). ${ }^{11}$ In addition, those patients with cystic fibrosis received antibiotic regimens on the basis of the results of perioperative cultures. Unique aspects of the perioperative management of the bilateral lobar recipient related to the lobar physiology, as well as donor management, have been previously described. ${ }^{11}$

\section{Definition of Variables}

Causes of death are reported on the basis of clinical findings, autopsy findings, or both. Flexible bronchoscopy and transbronchial biopsies were performed when clinically indicated and without the use of a routine surveillance protocol. Acute cellular rejection was determined by means of transbronchial biopsy and graded according to the classification of the International Society for Heart and Lung Transplantation (ISHLT) ${ }^{13}$ Bronchiolitis obliterans syndrome (BOS) was defined according to standard spirometric criteria. ${ }^{14}$ All patients, local or long distance, had formal pulmonary function tests (PFTs) performed with each clinic visit. Complete PFTs were performed at either our institution or the referring institution at 6 months, 1 year, and at least every year thereafter after transplantation. Results of PFTs from outside institutions were forwarded to our institution after each visit. Follow-up spirometry is complete in $100 \%$ of recipients. The recipient's functional status was graded as full (ability to work or attend school full-time), limited (part-time school or work), severely limited (needing chronic supplemental oxygen), or debilitated (wheelchair or bed bound).

\section{Statistical Analysis}

Data are presented as means \pm SD. Actuarial estimates of survival and freedom from obliterative bronchiolitis (OB) and BOS were derived by using life-table methods. For these analyses, KaplanMeier curves were compared with results of the log-rank (MantelHaenszel) test. Dichotomous variables for the following groups were compared to evaluate the risk of postoperative death by using a 2-tailed Fisher exact test and 95\% confidence intervals: male or female, adult or pediatric, indications for transplantation, preoperative ventilation, steroid use, and hospitalization status, as well as the presence or absence of rejection episodes and the relationship of the donor to the recipient. For all statistical analysis, GraphPad version 3.03 for Windows (GraphPad Software, Inc, San Diego, Calif) or SPSS for Windows (Release 9.0.1, SPSS, Inc) were used.

\section{Results}

\section{Demographics}

Demographics, indications for transplantation, and preoperative characteristics are presented for the overall cohort of lobar lung transplant recipients, as well as for adult and pediatric subgroups, in Table 1. The mean age of the overall cohort was $23.1 \pm 9.1$ years. Cystic fibrosis was the indication for transplantation in $84.4 \%$ of recipients. Other indications included pulmonary hypertension, idiopathic pulmonary fibrosis, bronchopulmonary dysplasia, and OB. In addition, 2 patients received lobar lung transplants for $\mathrm{OB}$ after bilateral cadaveric transplantation. Five lobar recipients received a second lobar transplant, 3 for primary graft failure and 2 for OB. Of lobar recipients, $67.5 \%$ were hospitalized, and $17.9 \%$ were intubated at the time of lobar transplantation.

\section{Overall Survival}

Overall follow-up is 374 patient-years (range, 0-9.8 years; mean, $3.0 \pm 2.8$ years). Sixty-three (51.2\%) deaths occurred during the follow-up period, 45 in adults and 18 in pediatric recipients. As shown in Figure 1, actuarial survival in the living lobar lung transplant recipients at 1,3 , and 5 years was $70 \%, 54 \%$, and $45 \%$, respectively. There was no difference in actuarial survival between adult or pediatric recipients of living lobar lung transplants (log-rank $P=$ $.65)$, as shown in Figure 2.

\section{Causes of Death}

Causes of death are listed in Table 2. Fifteen deaths occurred within 30 days of transplantation, with infection and primary graft failure being the most common causes. Twen- 


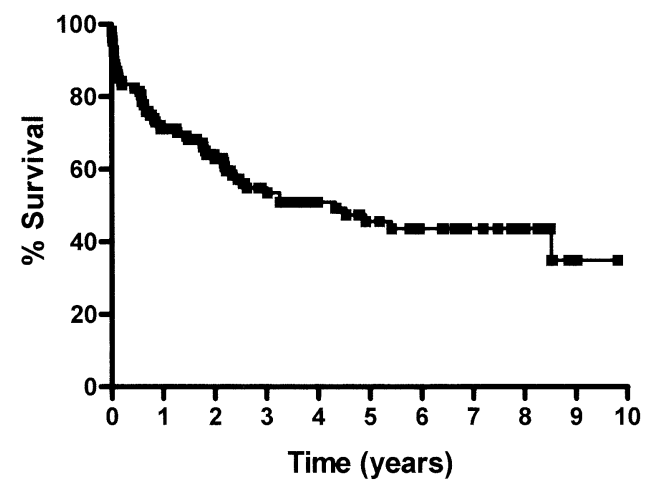

\begin{tabular}{l|ccccccccccr} 
Lobar Transplants & 0 & 1 & 2 & 3 & 4 & 5 & 6 & 7 & 8 & 9 & 10 \\
\hline Number at Risk & 123 & 85 & 68 & 49 & 36 & 30 & 25 & 19 & 12 & 3 & 1 \\
Actuarial Survival (\%) & & 70 & 63 & 54 & 50 & 45 & 42 & 42 & 42 & 35 & 35
\end{tabular}

Figure 1. Actuarial survival and number of patients at risk for the total cohort of living lobar lung transplant recipients.

TABLE 1. Demographics, indications for transplantation, and preoperative characteristics of living lobar lung transplant recipients

\begin{tabular}{|c|c|c|c|}
\hline & Overall & $\begin{array}{c}\text { Adult } \\
\text { recipients }\end{array}$ & $\begin{array}{c}\text { Pediatric } \\
\text { recipients }\end{array}$ \\
\hline \multicolumn{4}{|l|}{ Demographics } \\
\hline No. of patients & 123 & 84 & 39 \\
\hline Age $(y \pm S D)$ & $23.1 \pm 9.1$ & $27.4 \pm 7.7$ & $13.9 \pm 2.9$ \\
\hline Female sex $(\%)$ & $72(58.5)$ & $53(64.3)$ & $19(46.2)$ \\
\hline $\begin{array}{l}\text { Number of transplantations (or number undergoing } \\
\text { retransplantation) }\end{array}$ & $128(5)$ & $87(3)$ & $41(2)$ \\
\hline Recipient weight $(\mathrm{kg} \pm \mathrm{SD})$ & - & $49.9 \pm 8.9$ & $35.2 \pm 8.9$ \\
\hline Recipient height $(\mathrm{cm} \pm \mathrm{SD})$ & - & $163 \pm 8.6$ & $148 \pm 15$ \\
\hline \multicolumn{4}{|l|}{ Indication for transplantation } \\
\hline Cystic fibrosis (\%) & $108(84.4)$ & $76(87.4)$ & $32(78.1)$ \\
\hline Pulmonary hypertension (\%) & $5(3.9)$ & $0(0)$ & $5(12.2)$ \\
\hline Idiopathic pulmonary fibrosis $(\%)$ & $5(3.9)$ & $5(5.7)$ & $0(0)$ \\
\hline Bronchopulmonary dysplasia (\%) & $1(0.8)$ & $1(1.1)$ & $0(0)$ \\
\hline Obliterative bronchiolitis (\%) & $2(1.6)$ & $0(0)$ & $2(4.9)$ \\
\hline Obliterative bronchiolitis after cadaveric transplantation & $2(1.6)$ & $2(2.3)$ & $0(0)$ \\
\hline Primary graft failure after lobar transplantation & $3(2.3)$ & $2(2.3)$ & $1(2.4)$ \\
\hline Obliterative bronchiolitis after lobar transplantation & $2(1.5)$ & $1(1.2)$ & $1(2.4)$ \\
\hline \multicolumn{4}{|l|}{ Preoperative characteristics } \\
\hline Hospitalized at time of transplantation (\%) & $83(67.5)$ & $63(75.0)$ & $20(51.3)$ \\
\hline Ventilator dependent at time of transplantation (\%) & $22(17.9)$ & $17(20.2)$ & $5(12.8)$ \\
\hline
\end{tabular}

ty-two deaths occurred between 30 days and 1 year after transplantation, with infectious causes being the most common. Late death ( $>1$ year after transplantation) occurred in 26 patients, with infection and OB being the predominant causes.

For the overall cohort, infection was the predominant cause of death (52.4\%), with sepsis and pneumonia from Pseudomonas species, Staphylococcus species, and Aspergillus species being the most common causes. Death caused by CMV occurred in 3 patients. OB resulting in death occurred in $8(12.7 \%)$ recipients; the mean time to death in these patients was $4.1 \pm 2.1$ years. In addition, 2 lobar recipients underwent retransplantation for $\mathrm{OB}$ with 2 additional lobes at 2 and 4 years after the original transplantation; one patient died 2 months after retransplantation (because of CMV), and the other is alive 1 year after retransplantation. Primary graft dysfunction as a cause of death occurred in 5 patients at a mean of $25 \pm 26$ days after transplantation. Three additional patients had significant primary graft dysfunction postoperatively and received an additional lobe at 1,1 , and 6 weeks after the original transplantation. Of these patients, 2 died (one because of CMV and one because of Aspergillus species infection), and 1 is alive 7 years after retransplantation. Both patients who received lobar transplants for OB after cadaveric lung trans- 


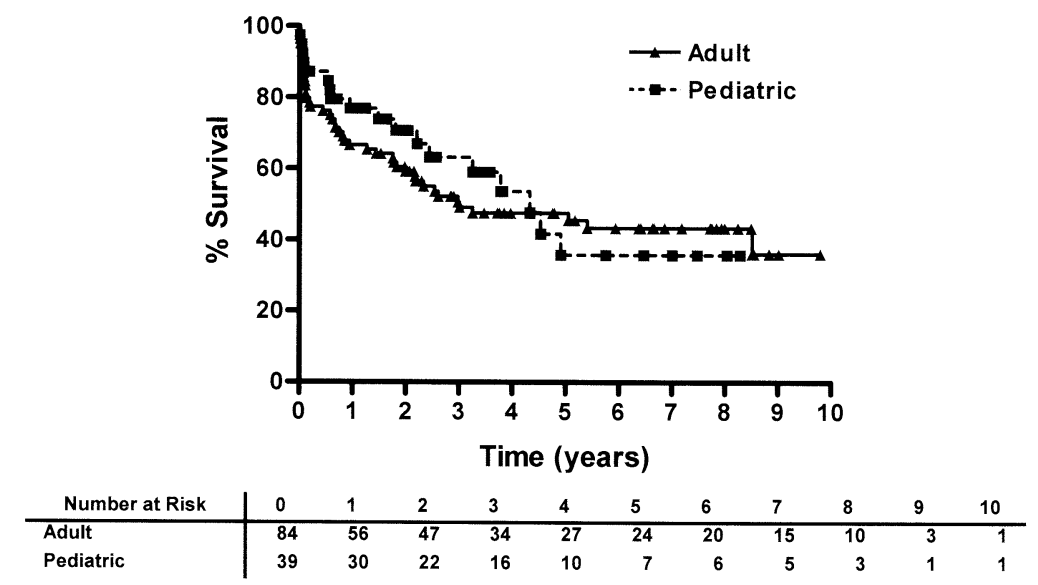

Figure 2. Actuarial survival and number of patients at risk for adult ( $\geq 18$ years of age) and pediatric ( $<18$ years of age) living lobar lung transplant recipients (log-rank $P=.65)$.

plantation died, one 35 days after lobar transplantation because of Aspergillus species infection, and the other 3 years after retransplantation from OB. Of the 5 pediatric patients undergoing transplantation for pulmonary hypertension, 4 are alive 2, 6.5, 7, and 8 years after transplantation, whereas 1 died 3.8 years after transplantation because of OB. Two of the 5 patients undergoing transplantation for pulmonary fibrosis are alive 1.8 and 8.6 years after transplantation, whereas 3 died 27, 45, and 70 days after transplantation from Aspergillus species infection, idiopathic thrombocytopenic purpura, and bacterial pneumonia, respectively. The patient with bronchopulmonary dysplasia died 6 years after transplantation from OB. The cause of death in patients with cystic fibrosis was predominantly infectious (28/52 deaths), with the remaining deaths resulting from the causes listed in Table 2. Other less common causes of death included liver failure, gastrointestinal bleeding, idiopathic thrombocytopenic purpura, bronchiectasis, anoxic brain injury, renal failure, diffuse alveolar disease, and one unknown cause. Noncompliance contributed to the death of at least 8 of these patients (12.7\% of all deaths), and chronic malnutrition and weakness resulting in pneumonia, multisystem organ failure, and ultimately death occurred in 2 recipients.

\section{Rejection Episodes}

The overall incidence of rejection was 0.8 episodes per patient. Of the 100 episodes of rejection seen in the 67 patients, $72 \%$ were unilateral, and $28 \%$ were bilateral. Fiftythree percent of rejection episodes were classified as grade A2 according to the ISHLT grading system, whereas 35\% were classified as grade A1, and $12 \%$ were classified as grade A3. Twenty-two (33\%) of the 67 recipients with rejection had multiple episodes, and 59\% of these multiple rejection episodes occurred in the same side distribution as with the initial rejection episode.
TABLE 2. Causes of death in living lobar lung transplant recipients by time after transplantation

\begin{tabular}{|c|c|c|c|c|}
\hline \multirow[b]{2}{*}{ Cause of death } & \multirow[b]{2}{*}{ Overall } & \multicolumn{3}{|c|}{ Time after transplantation } \\
\hline & & $\begin{array}{c}\text { Within } \\
30 \mathrm{~d} \\
\end{array}$ & $\begin{array}{c}\text { Between } \\
30 \mathrm{~d} \text { and } \\
1 \mathrm{y}\end{array}$ & $\begin{array}{c}\text { More than } \\
1 \mathrm{y}\end{array}$ \\
\hline Infection (\%) & $33(52.4)$ & $5(33.3)$ & $16(72.8)$ & $12(46.2)$ \\
\hline Bacterial sepsis & $9(27.3)$ & $1(20.0)$ & $3(18.8)$ & $5(41.7)$ \\
\hline Aspergillus species & $8(24.2)$ & $4(80.0)$ & $4(25.0)$ & $0(0)$ \\
\hline Pneumonia: other & $7(21.2)$ & $0(0)$ & $6(37.5)$ & $1(8.3)$ \\
\hline Pseudomonas species & $4(12.1)$ & $0(0)$ & $1(6.3)$ & $3(25.0)$ \\
\hline Cytomegalovirus & $3(9.1)$ & $0(0)$ & $1(6.3)$ & $2(16.7)$ \\
\hline Fungal sepsis & $1(3.0)$ & $0(0)$ & $1(6.3)$ & $0(0)$ \\
\hline EBV pneumonitis & $1(3.0)$ & $0(0)$ & $0(0)$ & $1(8.3)$ \\
\hline $\begin{array}{l}\text { Obliterative bronchiolitis } \\
\text { (\%) }\end{array}$ & $8(12.7)$ & $0(0)$ & $0(0)$ & $8(30.8)$ \\
\hline $1^{\circ}$ Graft dysfunction (\%) & $5(7.9)$ & $4(26.7)$ & $1(4.5)$ & $0(0)$ \\
\hline Emboli/thrombi (\%) & $4(6.3)$ & $2(13.3)$ & $1(4.5)$ & $1(3.8)$ \\
\hline Cerebral edema (\%) & $3(4.8)$ & $3(20.0)$ & $0(0)$ & $0(0)$ \\
\hline Malnutrition (\%) & $2(3.2)$ & $0(0)$ & $1(4.5)$ & $1(3.8)$ \\
\hline Others $(\%)^{*}$ & $8(12.7)$ & $1(6.7)$ & $3(13.7)$ & $4(15.4)$ \\
\hline Overall no. of deaths (\%) & 63 & $15(23.8)$ & $22(34.9)$ & $26(41.3)$ \\
\hline
\end{tabular}

EBV, Epstein-Barr virus.

*Other causes of death included liver failure, gastrointestinal bleeding, idiopathic thombocytopenic purpura, bronchiectasis, anoxic brain injury, renal failure, diffuse alveolar damage, and an unknown cause.

\section{Freedom From OB and BOS}

OB was pathologically confirmed in 17 (13.8\%) patients (9 adult and 8 pediatric patients). Two patients underwent another bilateral lobar lung transplantation, whereas 8 died of disease. Three additional adult patients are considered to have BOS on the basis of decreases in spirometric values, yielding an overall incidence of $16.3 \%$ in this cohort. Overall freedom from BOS and OB in adult recipients is $98 \%$, $82 \%$, and $76 \%$ at 1,3 , and 5 years, respectively. 


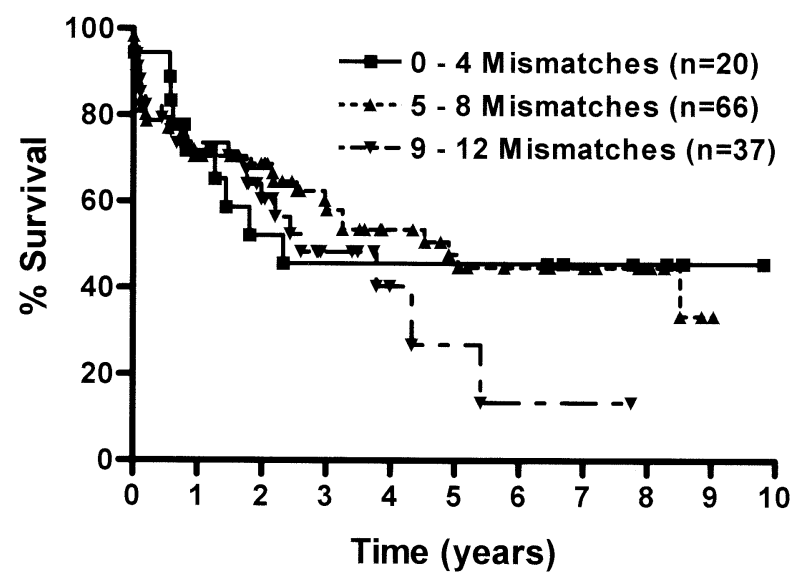

Figure 3. Actuarial survival according to the total number of HLA-A, HLA-B, and HLA-DR mismatches between the recipient and both donor lobes $(\log -\operatorname{rank} P=.56)$.

\section{HLA Mismatches}

HLA-A, HLA-B, and HLA-DR haplotypes for the recipients and the respective donor lobes were analyzed to determine whether there was a relationship between the number of HLA mismatches and survival. Because of the unusual aspect of this procedure involving 2 different donors for each recipient, the total number of mismatches could equal 12 , as opposed to 6 in living-donor kidney transplantation, which involves only one donor. When the numbers of HLA-A, HLA-B, and HLA-DR mismatches between the recipient and the 2 donor lobes were categorized into those with 0,1 to 2 , and 3 to 4 total mismatches, there was no influence on survival (data not shown). The total number of HLA-A, HLA-B, and HLA-DR mismatches between the recipient and donor lobes was also categorized into those recipients with 0 to 4,5 to 8 , and 9 to 12 total mismatches; there was no association with survival (Figure 3).

\section{Predictors of Death}

Fisher exact tests were performed to identify patient variables that might predict increased mortality. As shown in Table 3, the odds ratios were not significant for recipient age, sex, cystic fibrosis as an indication for transplantation, a diagnosis other than cystic fibrosis as an indication for transplantation, preoperative hospitalization status, preoperative steroid use, presence or absence of rejection episodes, or relationship of donor to recipient. The odds ratio for risk of death was greater than 2.5 when comparing those recipients undergoing lobar lung transplantation who were intubated preoperatively and for those undergoing retransplantation. Actuarial survival curves were generated to further examine the effect of preoperative intubation on survival, and recipients intubated preoperatively were found to have significantly worse outcomes than those patients not intubated $(P=.002$, Figure 4$)$. The time to $50 \%$ survival for intubated recipients was 0.44 years versus 4.91 years in nonintubated recipients. Of the 16 intubated patients who died, $9(56 \%)$ died of infection, with Aspergillus species being the predominant organism responsible for death in this subgroup (78\%). In addition, 7 of the 9 deaths caused by Aspergillus species infection in the overall cohort of lobar recipients occurred in patients intubated preoperatively. Actuarial survival curves comparing primary transplantations with retransplantations are shown in Figure 5.

\section{Functional Status}

At the present time, all 60 current survivors (39 adult and 21 pediatric patients) are either working or attending school full time, without any functional limitations. Three female recipients went through full-term pregnancy without any untoward events during gestation or delivery.

\section{Discussion}

The field of clinical lung transplantation has improved markedly over the past 3 decades as a result of advances in the areas of surgical technique, organ preservation, immunosuppressive drug therapy, and the prevention and treatment of infection. However, although the number of patients with end-stage lung disease placed on the waiting list has increased, the availability of cadaveric donor lungs has failed to increase to the same degree. ${ }^{2}$ In 1993, bilateral living-donor lobar lung transplantation was introduced by our group in response to the cadaveric lung donor shortage. ${ }^{1}$

In 1996, we reported our intermediate results with this procedure in a cohort of 27 adult and 10 pediatric recipients. ${ }^{4}$ Average follow-up at that time was 14 months, and 1 -year actuarial survival was $68 \%$. The lobar recipients were an extremely ill cohort of patients, primarily with cystic fibrosis, with 22 of the 37 transplantations being performed on an emergency basis within 72 hours of arrival at our institution. Infection was the predominant cause of death. In addition, pulmonary hemodynamics were acceptable in a subcohort study of these patients. From this analysis, it became clear that living lobar transplantation was a workable option for patients whose condition was deteriorating or acquiring characteristics that would make them unsuitable candidates for cadaveric lung transplantation. We now present an analysis of recipient outcomes for the 123 patients who have undergone this procedure at our institution in the last decade.

Cystic fibrosis remains the predominant indication for transplantation in these recipients. The high percentage of patients with cystic fibrosis undergoing transplantation in our experience reflects referral patterns, donor-to-recipient size-matching requirements, and psychosocial dynamics within this group of patients. As with our previous reports, this patient population continues to be a sick cohort, with $75 \%$ of adult and $51 \%$ of pediatric patients being hospital 


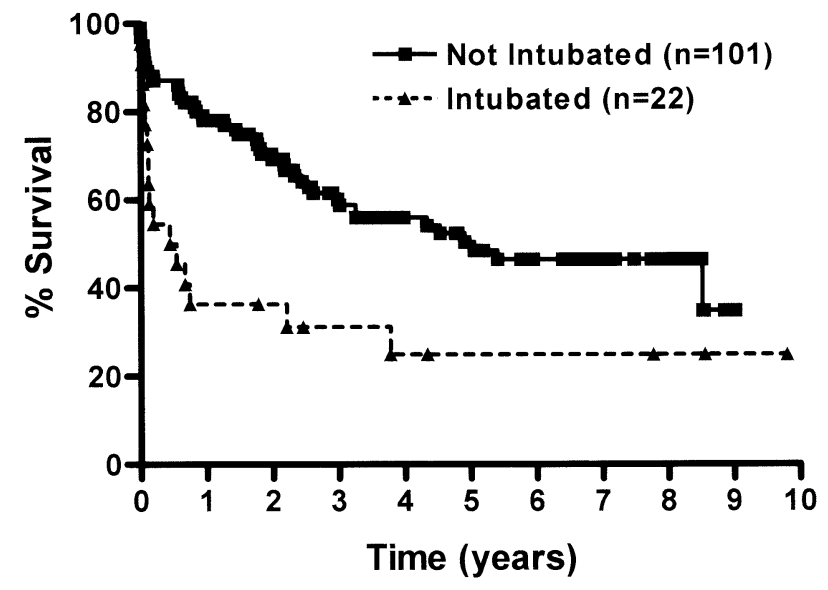

Figure 4. Actuarial survival on the basis of preoperative intubation status (log-rank $P=.002$ ).

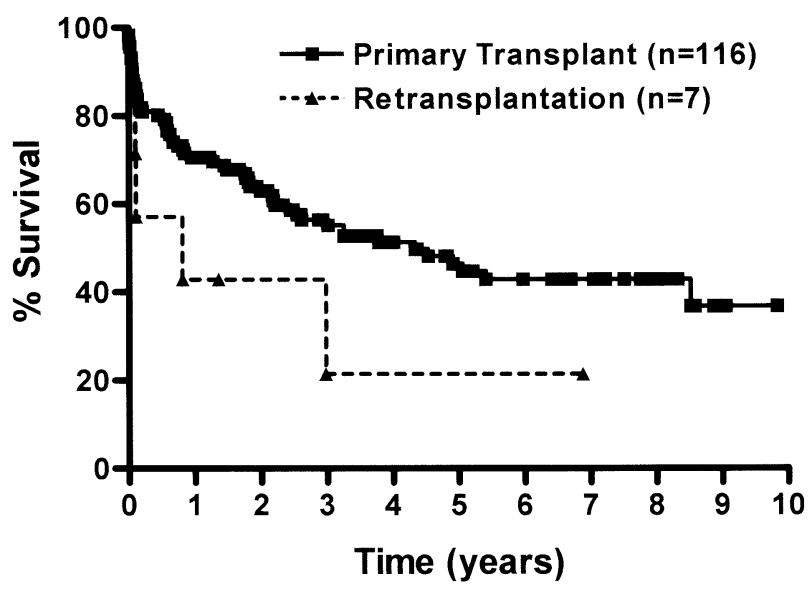

Figure 5. Actuarial survival comparing primary transplantation versus retransplantation (log-rank $P=.13)$.

TABLE 3. Risk of death by patient variables

\begin{tabular}{|c|c|c|c|c|c|}
\hline Characteristic subgroup & Variable & $\begin{array}{l}\text { Total no. } \\
\text { in group }\end{array}$ & $\begin{array}{l}\text { No. }(\%) \text { of } \\
\text { recipients } \\
\text { who died }\end{array}$ & $\begin{array}{c}\text { Odds ratio } \\
\text { (95\% confidence interval) }\end{array}$ & $P$ value \\
\hline \multirow[t]{2}{*}{ Sex } & Male & 51 & 25 & $0.86(0.42-1.76)$ & .72 \\
\hline & Female & 72 & 38 & & \\
\hline \multirow[t]{2}{*}{ Age } & Adult & 84 & 45 & $1.35(0.63-2.88)$ & .56 \\
\hline & Pediatric & 39 & 18 & & \\
\hline \multirow[t]{2}{*}{ Cystic fibrosis } & Yes & 103 & 52 & $0.83(0.32-2.18)$ & .81 \\
\hline & No & 20 & 11 & & \\
\hline \multirow{2}{*}{$\begin{array}{l}\text { Other indication than cystic fibrosis for } \\
\text { transplantation }\end{array}$} & Yes & 20 & 11 & $1.20(0.46-3.14)$ & .81 \\
\hline & No & 103 & 52 & & \\
\hline \multirow[t]{2}{*}{ Previous transplantation } & Yes & 7 & 5 & $2.50(0.47-13.4)$ & .44 \\
\hline & No & 116 & 58 & & \\
\hline \multirow[t]{2}{*}{ Hospitalized at time of transplantation } & Yes & 83 & 43 & $1.08(0.51-2.29)$ & 1.00 \\
\hline & No & 40 & 20 & & \\
\hline \multirow{2}{*}{ On ventilator at time of transplantation } & Yes & 22 & 16 & $3.06(1.11-8.47)$ & .03 \\
\hline & No & 101 & 47 & & \\
\hline \multirow{2}{*}{ On steroids at time of transplantation } & Yes & 42 & 19 & $0.69(0.33-1.47)$ & .35 \\
\hline & No & 81 & 44 & & \\
\hline \multirow{2}{*}{ Occurrence of $\geq 1$ rejection episode } & Yes & 67 & 32 & $0.74(0.36-4.79)$ & .47 \\
\hline & No & 56 & 31 & & \\
\hline \multirow[t]{2}{*}{$\geq 1$ Related donor } & Yes & 102 & 55 & $1.90(0.73-4.98)$ & .23 \\
\hline & No & 21 & 8 & & \\
\hline
\end{tabular}

bound at the time of transplantation. In addition, $17.9 \%$ were ventilator dependent at the time of transplantation. Despite the critical condition of many of these recipients, the overall actuarial survival of $70 \%, 54 \%$, and $45 \%$ at 1,3 , and 5 years, respectively, is comparable with that of reported double-lung cadaveric transplantation from the ISHLT Registry $(74 \%, 59 \%$, and $49.5 \%$ at 1,3 , and 5 years, respectively). ${ }^{15}$ Actuarial survival between adult and pediatric lobar recipients was equivalent. Infection continues to be the cause of death in the majority of patients. This likely reflects, once again, the large proportion of patients with cystic fibrosis in this cohort, but infection was also a common cause of death in patients undergoing transplantation for indications other than cystic fibrosis. The incidence of rejection has not changed since our previous report, with 0.8 episodes per patient. However, more rejection episodes appear to be synchronous than previously reported because $72 \%$ were unilateral and $28 \%$ were synchronous in the present report as opposed to the $98 \%$ unilateral episodes in our previous report. The distribution of grades of rejection remain similar because $53 \%$ of rejection episodes were classified as grade A2, 35\% were classified as grade A1, and 
$12 \%$ were classified as grade A3. Rates of OB have increased from our initial reports with further follow-up but are still lower than is generally reported in series of cadaveric transplantations. ${ }^{16,17}$

The role of class I and II HLA mismatches on lung transplantation outcomes remains incompletely understood. In a study of 3549 cadaveric lung transplantations using data from the United Network for Organ Sharing/ISHLT registry that examined the influence of HLA matching on survival, multivariate logistic regression demonstrated that the number of mismatches at the HLA-A and HLA-DR loci predicted 1-year mortality and that the total number of mismatches predicted 3- and 5-year mortality. ${ }^{18}$ The results of our analysis of HLA mismatches failed to show an association between the recipient and both donor lobes in terms of survival. The role of HLA mismatches in the setting of lobar lung transplantation is even more complicated than in the cadaveric setting, given that the number of potential mismatches is twice that seen with cadaveric transplantation or with living organ transplantations involving only one donor. On the basis of our results, we would not recommend restricting potential donors for recipients on the basis of the number of HLA-A, HLA-B, or HLA-DR mismatches between the recipient and the potential donor at the present time. Perhaps with greater follow-up and numbers of patients, the potential role of HLA mismatching in lobar transplantation will become better understood.

A major question regarding lobar lung transplantation that has been unanswered during the last decade has been defining when a potential recipient is too ill to justify placing 2 healthy donors at risk of donor lobectomy. Recipient age, sex, indication for primary transplantation, prehospitalization status, steroid use preoperatively, relationship of the donor to the recipient, and the presence or absence of rejection episodes postoperatively all did not appear to influence overall mortality. However, those patients on ventilators preoperatively, as well as those undergoing retransplantation after either a previous cadaveric or lobar lung transplantation, had significantly increased odds ratios for postoperative death. In addition, overall actuarial survival was markedly lower in intubated versus nonintubated patients. It would thus appear that intubated patients are at significant risk of poor outcomes, whereas those undergoing retransplantation are at an increased risk. This experience is not that dissimilar to the cadaveric experience, in which intubated patients have higher 1-year mortalities, and retransplantations have decreased 3- and 5-year survival. ${ }^{2,15}$ A similar experience with a smaller number of lobar transplantations has been reported by the Washington University group. ${ }^{19}$

A fundamental aspect of living lobar lung transplantation remains appropriate recipient selection and timing. Although the question of whether a recipient is too well to justify placing 2 donors at risk remains unanswered by this report, the question of whether a recipient is too ill to justify placing 2 donors at risk is now partially answered. On the basis of the findings in this report, those patients on ventilators preoperatively and those patients having undergone a previous lung transplantation appear to be at high risk for adverse outcomes with this procedure, and we would recommend caution in these subgroups of patients because of the inherent risk to the donors and the poor outcomes in these recipients. Despite this high-risk patient group, our results clearly indicate that this alternative procedure has been life saving in severely ill patients who would either die or become unsuitable recipients before a cadaveric organ becomes available. Although cadaveric transplantation is preferable because of the risk to the donors, living lobar lung transplantation should continue to be used under properly selected circumstances.

We thank Earl H. Leonard, MS, for statistical assistance with this article.

\section{References}

1. Starnes VA, Barr ML, Cohen RG. Lobar transplantation. Indications, technique, and outcome. J Thorac Cardiovasc Surg. 1994;108:403-11.

2. Grover FL, Barr ML, Edwards LB, Martinez FJ, Pierson RN, Rosengard BR, et al. Scientific Registry of Transplant Recipients (SRTR) report on the state of transplantation: thoracic transplantation. Am J Transplant. 2003;3:91-102.

3. Rosengard BR, Feng S, Alfrey EJ, Zaroff JG, Emond JC, Henry ML, et al. Report of the Crystal City meeting to maximize the use of organs recovered from the cadaver donor. Am J Transplant. 2002;2:701-11.

4. Starnes VA, Barr ML, Cohen RG, Hagen JA, Wells WJ, Horn MV, et al. Living-donor lobar lung transplantation experience: intermediate results. J Thorac Cardiovasc Surg. 1996;112:1284-91.

5. Starnes VA, Barr ML, Schenkel FA, Horn MV, Cohen RG, Hagen JA, et al. Experience with living-donor lobar transplantation for indications other than cystic fibrosis. J Thorac Cardiovasc Surg. 1997;114: 917-22.

6. Barr ML, Schenkel FA, Cohen RG, Barbers RG, Fuller CB, Hagen JA, et al. Recipient and donor outcomes in living related and unrelated lobar transplantation. Transplant Proc. 1998;30:2261-3.

7. Woo MS, MacLaughlin EF, Horn MV, Wong PC, Rowland JM, Barr ML, et al. Living donor lobar lung transplantation: the pediatric experience. Pediatr Transplant. 1998;2:185-90.

8. Starnes VA, Woo MS, MacLaughlin EF, Horn MV, Wong PC, Rowland JM, et al. Comparison of outcomes between living donor and cadaveric lung transplantation in children. Ann Thorac Surg. 1999;68: 2279-84

9. Barr ML, Baker CJ, Schenkel FA, Bowdish ME, Bremner RM, Cohen RG, et al. Living donor lung transplantation: selection, technique, and outcome. Transplant Proc. 2001;33:3523-7.

10. Woo MS, MacLaughlin EF, Horn MV, Szmuszkovicz JR, Barr ML, Starnes VA. Bronchiolitis obliterans is not the primary cause of death in pediatric living donor lobar lung transplant recipients. J Heart Lung Transplant. 2001;20:491-6.

11. Baker CJ, Barr ML, Schenkel FA, Starnes VA. Living donor lung transplantation. In: Baumgartner WA, Reitz B, Kasper E, Theodore J, editors. Heart and lung transplantation. 2nd ed. Philadelphia, Pa: WB Saunders; 2002.

12. Schenkel FA, Barr ML, Starnes VA. Living-donor lobar lung transplantation: donor evaluation and selection. In: Norman DJ, Turka LA, editors. Primer on transplantation. 2nd ed. Moorestown, NJ: American Society of Transplantation; 2001. 
13. Billingham ME, Cary NR, Hammond ME, Kemnitz J, Marboe C, McCallister HA, et al. A working formulation for the standardization of nomenclature in the diagnosis of heart and lung rejection: Heart Rejection Study Group. The International Society for Heart Transplantation. J Heart Transplant. 1990;9:587-93.

14. Estenne M, Maurer JR, Boehler A, Egan JJ, Frost A, Hertz M, et al. Bronchiolitis obliterans syndrome 2001: an update of the diagnostic criteria. J Heart Lung Transplant. 2002;21:297-310.

15. Hertz MI, Taylor DO, Trulock EP, Boucek MM, Mohacsi PJ, Edwards LB, et al. The registry of the international society for heart and lung transplantation: nineteenth official report-2002. J Heart Lung Transplant. 2002;21:950-70.

16. Reichenspurner H, Girgis RE, Robbins RC, Yun KL, Nitschke M, Berry GJ, et al. Stanford experience with obliterative bronchiolitis after lung and heart-lung transplantation. Ann Thorac Surg. 1996;62: 1467-73.

17. Meyers BF, Lynch J, Trulock EP, Guthrie TJ, Cooper JD, Patterson GA. Lung transplantation: a decade of experience. Ann Surg. 1999; 230:362-71

18. Quantz MA, Bennett LE, Meyer DM, Novick RJ. Does human leukocyte antigen matching influence the outcome of lung transplantation? An analysis of 3,549 lung transplantations. J Heart Lung Transplant. 2000;19:473-9.

19. Huddleston CB, Bloch JB, Sweet SC, De la Morena M, Patterson GA, Mendeloff EN. Lung transplantation in children. Ann Surg. 2002;236: 270-6.

\section{Discussion}

Dr G. Alexander Patterson (St Louis, Mo). Dr Starnes, you and your colleagues should be congratulated. I think it is a monumental contribution. We all know that the donor supply is limited, and there are a number of different options. You can sit tight and do nothing, or you can do something about it, and that is exactly what you and your colleagues have done. We have performed a smaller number of these procedures, and I am well aware of the team that is required to conduct this kind of work and to achieve the results. You should be complimented on that as well.

I have a couple of questions. You did a detailed analysis of the HLA status of donors and recipients side by side. You noticed no difference in HLA typing among those patients who had a rejection episode. As a corollary, was there anything peculiar about those patients who did not have rejection on one side? Was there something unusual or some identifier in the donors of those unilateral lobes that did not reject? Can we make some prediction for the future development of BOS? How did you determine that a patient had unilateral BOS? How many of those patients were there? Was there something particularly identifiable about those specific patients?

Also, in this procedure we have to be aware of the donors, and the article does not comment on the results of donors. Could you take an opportunity now to share with us some donor information? How did the donors do? What was their mortality? What was their morbidity? How do you accomplish a follow-up program in the donors, particularly for those donors whose recipients experience a perioperative or late-term death?

Dr Starnes. Thank you, Dr Patterson. Those are extremely nice comments.

In this study, we only analyzed the relationship of survival to total HLA antigen mismatches. Development of BOS was hard to predict, whether unilateral or bilateral. A diagnosis of obliterative bronchiolitis was made in $16 \%$ of the cohort using biopsy or autopsy end points. An in-depth analysis of the relationship of outcomes and rejection episodes to HLA class I and II mismatches is underway, and we should have those results soon.

With regard to the donors, we have had no mortalities in this group of patients. We have operated on 253 patients for these 128 recipients. We have had some complications, mostly prolonged air leaks of greater than 5 days in about $8 \%$, and we had some arrhythmias in about $3 \%$.

As we follow these patients, and we consider them to be long-term patients, we performed a study to try to understand whether these patients would donate again, and as you would predict, $90 \%$ of them said they would. The $10 \%$ that said they were not sure or probably would not were in those who donated to recipients who died in the hospital.

Therefore overall, we think it is a safe operation. We do not underestimate the risk that we put these donors under each day, and that is the reason that we would limit this operation to patients who cannot wait for a cadaveric organ.

Dr Soon J. Park (Minneapolis, Minn). Most of your experience involves patients with cystic fibrosis. Would you care to elaborate on the utility of this operation for other patients, such as those with either pulmonary fibrosis or people with primary pulmonary hypertension?

Dr Starnes. As you noted in the slide during the presentation, each of those categories had about 4 or 5 patients in them, and I know that in the pulmonary hypertensive group, those patients have done really quite well: we had no operative deaths in those groups, and in the long term, we have 3 of the 5 patients still alive at greater than 5 years out. In the pulmonary fibrosis group we had 5 patients; again, immediate operative survival was excellent. We had 3 late deaths caused by infection.

Dr Fred A. Crawford, Jr (Charleston, SC). Vaughn, I believe that in your abstract you indicated that the second leading cause of death was noncompliance, which seemed to be unusually high. Is this a function of this particular patient population, or is this something that you have learned to screen for better since then? Could you comment on that?

Dr Starnes. Yes, this is a particular problem in the pediatric age group; that is where we had a lot of our pediatric deaths. We have had, over the last 3 years, 8 deaths caused by teenagers primarily not taking their medications, and this is a huge problem. Obviously we are trying to screen for it better, but it continues to be a problem that keeps coming up in our program, and it is mainly a pediatric subgroup problem.

Sir Magdi H. Yacoub (London, United Kingdom). Congratulations on your fantastic efforts. It is a bit disappointing that the incidence of rejection and $\mathrm{OB}$ are comparable; everybody expected them to be better. What do you think the cause for that is, because these organs have not been subjected to brain death, and we thought that that would have an effect? And with how many did you have zero HLA-DR mismatch? And what was your method of organ preservation? Do you think that has something to do with it?

Dr Starnes. As it relates to the incidence of OB in adults, I think the $24 \%$ incidence of OB is actually a little lower than we see in cadaveric transplantation. Was it dramatically lower? No. I think we still have the problems of viral infections precipitating a rejection episode, such as CMV, although it is less of a problem 
today than in the past. I think all these do contribute to the development of OB. Again, noncompliance in the pediatric age group in particular was a real problem for us that led to rejection episodes and then finally to OB. Sir Magdi, I really do not have an answer. I wish I did.
As it relates to preservation of the organ, we used a standard flush, both antegrade and retrograde, and preservation I do not think is really an issue because it is a very short ischemia time, usually less than an hour between harvest and implantation, because it is usually done in adjacent operating rooms.

\section{ON THE MOVE?}

Don't miss a single issue of the journal! To ensure prompt service when you change your address, please photocopy and complete the form below.

Please send your change of address notification at least six weeks before your move to ensure continued service. We regret we cannot guarantee replacement of issues missed due to late notification.

\section{JOURNAL TITLE:}

Fill in the title of the journal here.

\section{OLD ADDRESS:}

Affix the address label from a recent issue of the journal here.

\section{NEW ADDRESS:}

Clearly print your new address here.

Name

Address

City/State/ZIP

\section{COPY AND MAIL THIS FORM TO:}

Elsevier Inc.

Subscription Customer Service

6277 Sea Harbor Dr

Orlando, FL 32887
OR FAX TO:

407-363-9661
OR PHONE:

800-654-2452

Outside the U.S., call

407-345-4000 